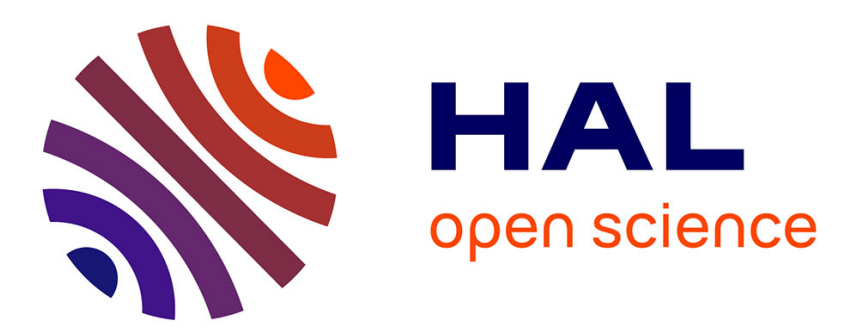

\title{
Room-Temperature CO Oxidation Catalyst: \\ Low-Temperature Metal-Support Interaction between Platinum Nanoparticles and Nanosized Ceria
}

S. Gatla, Daniel Aubert, G. d'Agostini, O. Mathon, S . Pascarelli, T. Lunkenbein, M. G. Willinger, H. Kaper

\section{To cite this version:}

S. Gatla, Daniel Aubert, G. d'Agostini, O. Mathon, S . Pascarelli, et al.. Room-Temperature CO Oxidation Catalyst: Low-Temperature Metal-Support Interaction between Platinum Nanoparticles and Nanosized Ceria. ACS Catalysis, 2016, 6 (9), pp.6151-6155. 10.1021/acscatal.6b00677 . hal01378621

\section{HAL Id: hal-01378621 \\ https://hal.science/hal-01378621}

Submitted on 8 Mar 2021

HAL is a multi-disciplinary open access archive for the deposit and dissemination of scientific research documents, whether they are published or not. The documents may come from teaching and research institutions in France or abroad, or from public or private research centers.
L'archive ouverte pluridisciplinaire HAL, est destinée au dépôt et à la diffusion de documents scientifiques de niveau recherche, publiés ou non, émanant des établissements d'enseignement et de recherche français ou étrangers, des laboratoires publics ou privés. 


\title{
Room-temperature $\mathrm{CO}$ oxidation catalyst: low temperature metal- support interaction between platinum nanoparticles and nanosized ceria
}

\author{
Suresh Gatla, ${ }^{\dagger}$ Daniel Aubert, ${ }^{\ddagger}$ Giovanni Agostini, ${ }^{\dagger}$ Olivier Mathon, ${ }^{\dagger}$ Sakura Pascarelli, ${ }^{\star \dagger}$ \\ Thomas Lunkenbein, § Marc Georg Willinger,§ Helena Kaper*ł \\ † European Synchroton Radiation Facility, 71, Ave des Martyrs, 38 ooo Grenoble, France \\ ‡ Ceramic Synthesis and Functionalization Laboratory, UMR 3080, CNRS/Saint-Gobain CREE, 550, Ave Alphonse \\ Jauffret, 84306 Cavaillon, France \\ § Fritz-Haber-Institut der Max-Planck-Gesellschaft, Department of Inorganic Chemistry, Faradayweg 4-6, 14195 \\ Belin, Germany
}

\begin{abstract}
Platinum nanoparticles dispersed on nanosized ceria are active for CO oxidation at room temperature after hydrogen pretreatment. High angular annular dark field -scanning transmission electron microscopy (HAADF-STEM) analysis of the reduced catalyst shows spreading of the $1 \mathrm{~nm}$ sized platinum particles under the electron beam, characteristic for two dimensional strong metal-support interaction. In-situ X-ray absorption fluorescence spectroscopy (XAFS) reveals a $\mathrm{Pt}-\mathrm{O}$ distance of $2.1 \AA$, which is significantly longer than the $\mathrm{Pt}-\mathrm{O}$ distance in $\mathrm{PtO}_{2}$ (2.0 $\AA$ ). This elongated Pt-O distance can be related to interaction of the platinum species with cerium oxide in form of low temperature active species-support interaction. These findings contribute to the general understanding of catalytic systems operating at low temperature.
\end{abstract}

KEYWORDS CO oxidation, Metal-support interaction, in-situ x-ray absorption spectroscopy, platinum cerium oxide catalyst, heterogeneous catalysis.

\section{Introduction}

Catalysts operating effectively at room temperature are a challenging class of materials covering applications as varied as the cold start of engines to indoor air quality. Room temperature activity is most often reported for $\mathrm{CO}$ or formaldehyde oxidation. ${ }^{1-4}$ Most non-noble metal systems, such as Hopcalites (copper manganese oxides) ${ }^{5,6}$ or $\mathrm{Co}_{3} \mathrm{O}_{4}{ }^{7}$ lack stability with time and/or in presence of moisture. More stable systems are often based on platinum nanoparticles deposited on reducible supports, $, 2,3,8$ demonstrating the importance of tuning both, the metallic phase and the support material.

In general, the catalytic performance of an active phase can be strongly influenced by interaction with the support material. As early as the seventies, Tauster reported on the so-called SMSI (strong metal-support interaction) for noble metals supported onto $\mathrm{TiO}_{2},{ }^{9}$ however, this important effect is observed at higher temperatures. Recently, attention has focused on the local environment between the active species and the support $\mathrm{t}^{10-13}$, e.g. on the interactions of support atoms in close contact to the active phase. The group of Illas reported on platinum-cerium oxide interactions on the nanoscale. ${ }^{14,15}$ The authors observe two main characteristics of this catalyst: an electron transfer from platinum to ceria and an oxygen transfer from ceria to platinum at the interface between nanosized ceria and platinum nanoparticles.

The application of ceria in catalysis has been recently reviewed by Montini et al. ${ }^{16} \mathrm{Among}$ the vast literature on ceria, nanosized ceria plays an important role as catalyst support due to the increased amount of surface oxygen defects as compared to microcrystalline ceria. ${ }^{17-19}$ The role of ceria supports and in peculiar oxygen ion vacancies has been described for numerous reactions, such as $\mathrm{CO}$ oxidation, ,,20-22 water-gas shift reaction, ${ }^{17,23-26} \mathrm{NO}_{x}$ abatement $^{27,28}$ preferential oxidation of CO (PROX)..$^{29,30}$ Next to the acknowledged effect of oxygen ion vacancies on the catalytic performance, also the presence of noble metals can change the ceria surface properties. It has been shown more than thirty years ago that the $\mathrm{Ce}-\mathrm{O}$ bond is 
weakened by the presence of metals and thus renders the surface more reducible. ${ }^{31}$ This concept usually lowers the reaction temperature. However, while the effect is wellestablished, the behavior of this system at low temperature (close to room temperature) has rarely been studied using operando characterization techniques. One recent example is the work of Ke et al. on $\mathrm{PtO}_{\mathrm{x}}$ clusters deposited onto $\mathrm{CeO}_{2}$ nanowires. ${ }^{22}$ In their work, the authors show strong interaction between the $\mathrm{PtO}_{\mathrm{x}}$ clusters and the ceria (110) surface using in-situ spectroscopic techniques coupled with DFT calculation. The catalytic performance of the $\mathrm{PtO}_{\mathrm{x}}$ clusters is strongly influenced by oxygen coordination around platinum: a too high coordination and thus stabilization of the Pt inactivates the nanoclusters. The present study focusses on platinum nanoparticles deposited on nanosized ceria active at room temperature. Insights into the working principles of these $\mathrm{Pt} / \mathrm{CeO}_{2}$ catalysts during low temperature $\mathrm{CO}$ oxidation are reported using HAADF-STEM analysis and operando XAFS measurements combined with simulation.

\section{Results and Discussion}

Figure 1 shows $\mathrm{CO}$ oxidation light-off curves for as-prepared and in-situ reduced $2.5 \mathrm{wt}-\% \mathrm{Pt} / \mathrm{CeO}_{2}$ samples. While oxidation takes place only at relatively high temperature for the as-prepared samples, in-situ reduced samples are already active at room temperature (10 \% conversion of $\mathrm{CO}$, e.g. $600 \mathrm{ppm})$. Upon cycling, room temperature conversion of $\mathrm{CO}$ diminishes, but the catalyst remains active and stabilizes after the third cycle. In comparison to recent advances in Pt-based CO catalysts, the present catalyst works at lower platinum loading (2.5 wt $\%$ as compared to 12 wt- $\%$ loading) 3 and converts more $\mathrm{CO} \quad(600 \mathrm{ppm}$ at room temperature

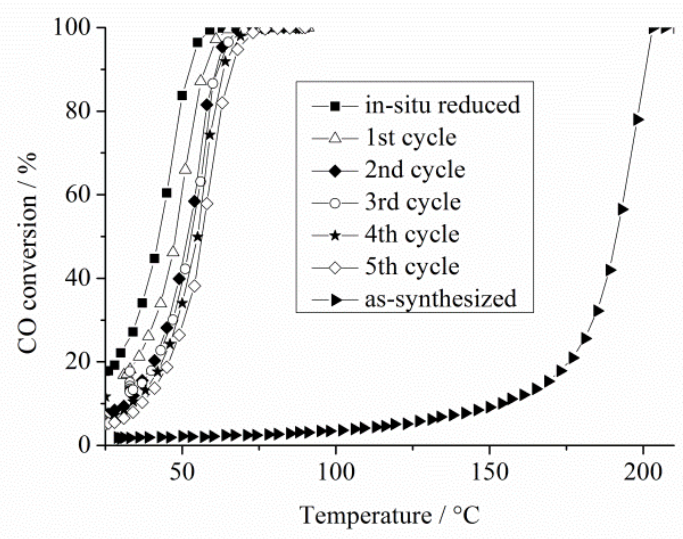

Figure 1. Light-off curves for $\mathrm{CO}$ oxidation of the as-prepared, in-situ reduced and cycled $2.5 \mathrm{wt}-\% \mathrm{Pt} / \mathrm{CeO}_{2}$ catalysts.

compared to $100 \mathrm{ppm}$ for a $\mathrm{Pt} / \mathrm{TiO} 2$ system). ${ }^{32}$ This result is somewhat surprising considering the simplicity of the system: we use pure cerium oxide without additional dopants, often introduced to improve the catalytic activity due to the creation of oxygen ion vacancies.

The Brunauer-Emmett-Teller surface area decreases from $97 \mathrm{~m}^{2} / \mathrm{g}$ (CeO2 support) to $82 \mathrm{~m}^{2} / \mathrm{g}$ upon impregnation (see Table $\mathrm{S} 1$ ). After hydrogen treatment, the specific surface area remains stable $\left(81 \mathrm{~m}^{2} / \mathrm{g}\right)$, thus showing that the catalytic performance is related to structural changes of Pt and not the surface area. The X-ray diffraction (XRD) patterns contain solely diffraction peaks of the fluorite phase $\mathrm{CeO}_{2}$, no other phases from platinum metal or platinum oxide are visible. The coherent scattering domain size of $\mathrm{CeO}_{2}$ as derived from Rietveld analysis is $9 \mathrm{~nm}$ for all samples (see Table $\mathrm{S} 1$ ). The structure of the catalyst can be best described by imaging the catalysts with electron microscopic techniques such as HRTEM and/or high angle annular darkfield - scanning TEM (HAADF-STEM). The corresponding micrographs of the $\mathrm{Pt} / \mathrm{CeO}_{2}$ catalysts after reductive activation in hydrogen and after $\mathrm{CO}$ oxidation are shown in Figure 2. The HRTEM image of Figure 2a displays a highly crystalline ceria support, which is terminated by stepped surfaces. No amorphous layer was observed at the ceria surface. In combination with the HAADF-STEM image presented in Figure $2 \mathrm{~b}$, these images indicate that the Pt nanoparticles are well-dispersed over the ceria support and exhibit a particle size of around $1 \mathrm{~nm}$. After reductive activation in hydrogen some of the ill-defined Pt nanoparticles (Figure 2c) spread along the ceria surface, after stimulation by the electron beam within the first $37 \mathrm{~s}$ (see supporting information movie $\mathrm{Ml}$ ). In addition, an increased lattice spacing (3.37 $\AA$ ) of the (111) planes of ceria is observed. During the prevailing time of the catalytic reaction the (111) lattice spacing is reduced to $3.21 \AA$, which is within the error range of the expected (111) lattice spacing ( $3.18 \AA$ ) for ceria. After $\mathrm{CO}$ oxidation, some of the Pt nanoparticles are slightly increased, as seen by the HAADF-STEM images in Figure $2 \mathrm{e}$ and $2 \mathrm{f}$. In addition, some atomic Pt clusters are observed. No spreading of the Pt nanoparticles along the surface of $\mathrm{CeO}_{2}$ was found even after the exposure to the electron beam for $302 \mathrm{~s}$ (Figure 2f, see supporting information movie $\mathrm{M}_{2}$ ). The different behavior under the electron beam of the reduced and spend samples suggests a structural modification of the platinum species during the catalytic test reaction. After hydrogen treatment and the catalytic testing, the Pt species are not covered by $\mathrm{CeO}$. However, the spreading of the reduced Pt nanoparticles on the ceria surface suggests the presence of the so called two dimensional strong metal support interaction as introduced by van Delft et al.33 Mobility and spreading of noble metal nanoparticles on ceria due to strong particle-surface interaction has been described in the literature, ${ }^{34-36}$ but to the best of our knowledge has not been described in the 


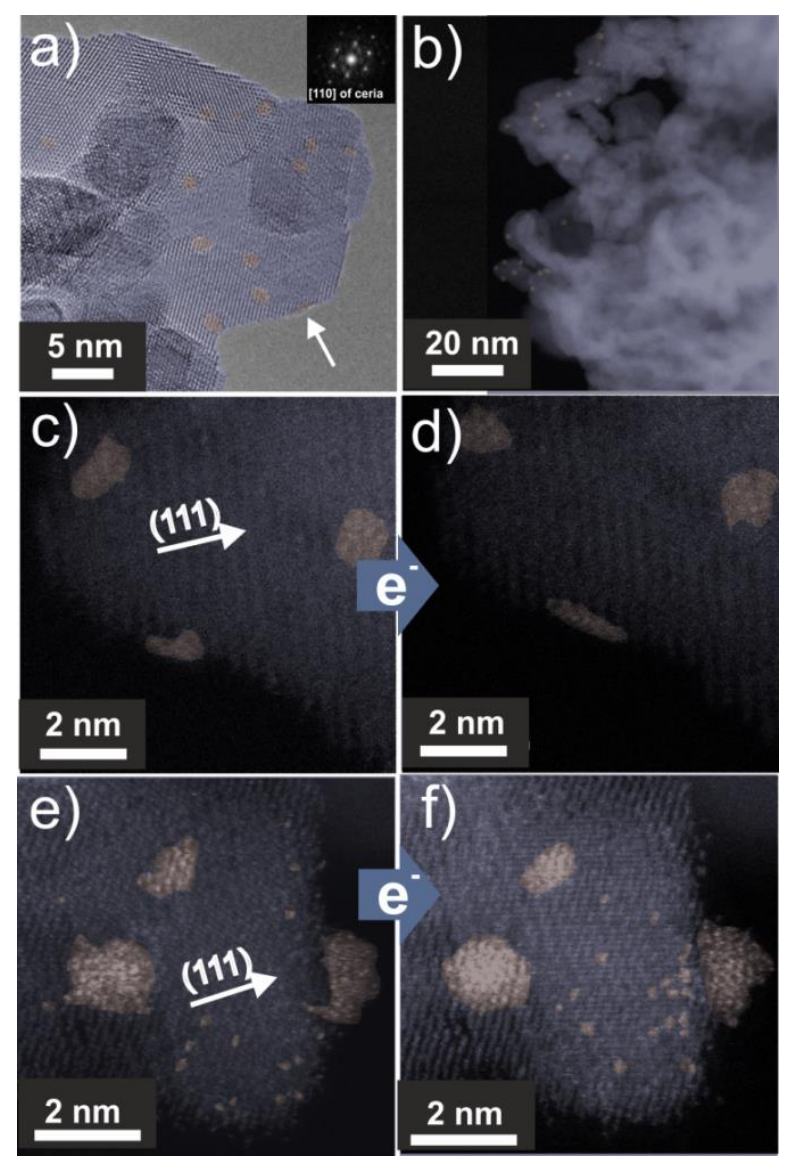

Figure 2. (S)TEM images of $\mathrm{Pt} / \mathrm{CeO}_{2}$ catalysts. a) HRTEM image of Pt nanoparticles supported on ceria. The arrow in a) points to a Pt nanoparticle spread on the surface of ceria. The inset shows the power spectrum of the ceria support. b) to d) HAADF-STEM images of $\mathrm{Pt} / \mathrm{CeO}_{2}$ catalyst after reductive activation in $\mathrm{H}_{2}$ at different magnifications. c) Atomic resolution HAADF-STEM image and (d) corresponding HAADF-STEM image after exposure to the electron beam for $37 \mathrm{~s}$. e) HAADF-STEM image after CO oxidation and f) HAADF-STEM image of the same position after exposure to the electron beam for $302 \mathrm{~s}$. The ceria support is highlighted in blue, whereas the Pt nanoparticles are depicted in red. The original images are given in the supporting information, Figure $\mathrm{S}_{2}$.

form of spreading under the electron beam. Further investigations under in-situ conditions will be needed to understand the role of the spreadable particles on the catalytic reactions, which is beyond the scope of the current work. However, since the spend catalyst does not spread, the initially present very small particles seem to be less stable. The structural changes observed might also explain the decrease in catalytic activity after the first cycle. In order to draw a more detailed picture of the electronic and structural properties of the platinum and cerium spe- cies during reduction and $\mathrm{CO}$ oxidation, we used operando XAFS coupled with mass spectrometry (MS). Details on the experimental setup (Figure $\mathrm{S}_{2}$ ), Pt L3 and $\mathrm{Ce}_{3} \mathrm{~L}_{3}$ XAFS measurements, in-situ treatment conditions, $\mathrm{CO}$ activity profiles (Figure $\mathrm{S}_{3}$ ) and data analysis procedures are summarized in the supporting information. The main observation from $\mathrm{Ce} \mathrm{L}_{3}$ edge data (Figure $\mathrm{S}_{4}$ ) is that the amount of $\mathrm{Ce}^{3+}$ increases from $15 \%$ to $28 \%$ during hydrogen treatment. The sample reoxidizes immediately under $\mathrm{CO}$ oxidation conditions, being in agreement with HRTEM observations. Presumably, the catalytic performance is not determined by the overall $\mathrm{Ce}^{3+}$ concentration, but by $\mathrm{Ce}^{3+}$ located in vicinity to the noble metal, which is coherent with recent publication on the role of $\mathrm{Ce}^{3+}$ in $\mathrm{CO}$ oxidation. ${ }^{22,37,38}$ These active $\mathrm{Ce}^{3+}$-species are short lived. $3^{8}$ Therefore, the concentration and its role cannot be observed using our technique and is beyond the scope of this work. Significant changes during reduction and $\mathrm{CO}$ oxidation are observed in the Pt L3 EXAFS spectra. Figure 3 shows the amplitude of the Fourier Transformation (FT) EXAFS spectra of the as-prepared and in-situ reduced samples together with the best fit and the contributions from Pt-O and Pt-Pt.
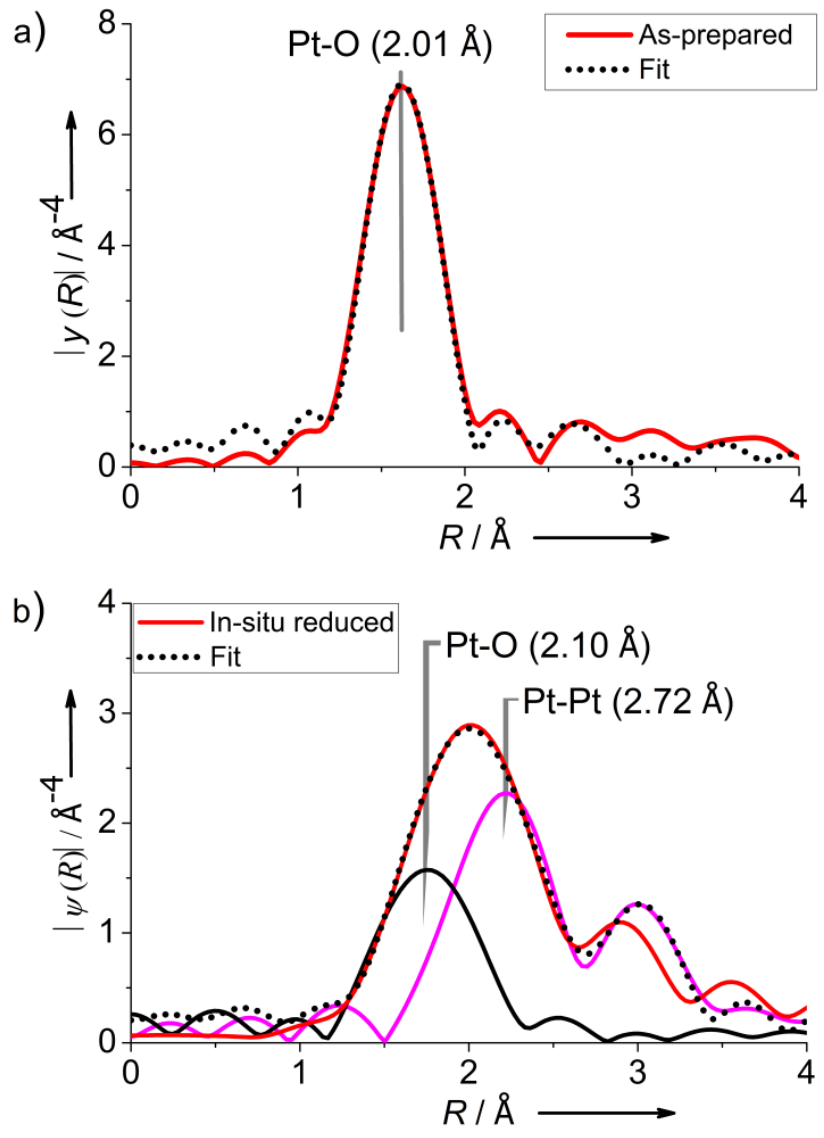

Figure 3. FT of EXAFS spectra of a) as-prepared and b) in-situ reduced $2.5 \mathrm{wt}-\% \mathrm{Pt} / \mathrm{CeO}_{2}$ catalysts together with the best fits and the ccontributions of Pt-O, Pt-Pt. 

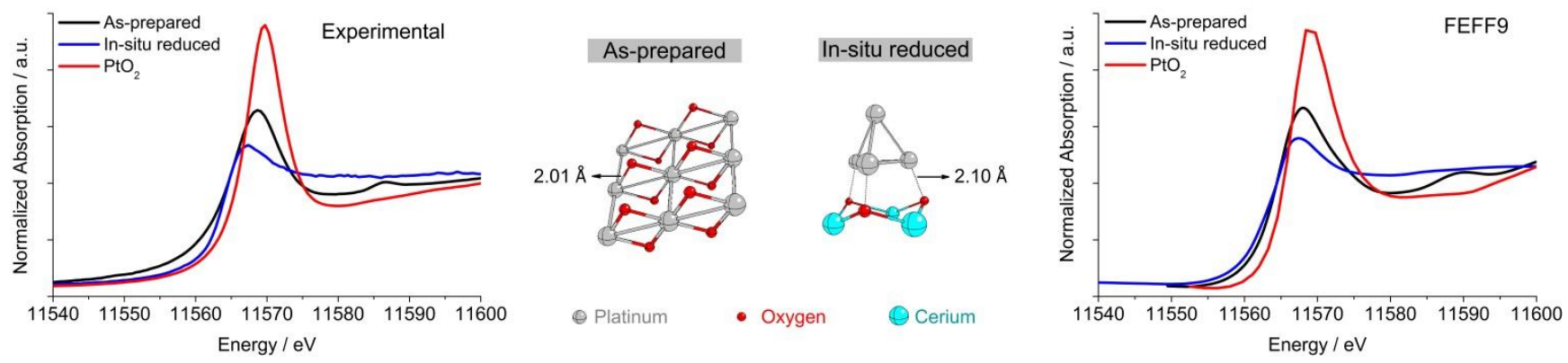

Figure 4. Experimental $\mathrm{PtL}_{3}$-edge XANES patterns of the as-prepared as well as in-situ reduced $2.5 \mathrm{wt}-\% / \mathrm{CeO}_{2}(\mathrm{left}$ side) and the simulated ones with FEFF9 code (right side) along with the proposed model structures (middle panel).

EXAFS analysis (Table S2, S3) shows that the local environment of Pt in the as-prepared sample is very similar to that in platinum oxide (only oxygen nearest neighbors), with a Pt-O bond distance of $2.01 \pm 0.01 \AA$ ( $\mathrm{PtO}_{2}$ : $2.00 \pm 0.01 \AA$ ) . The main difference between our sample and $\mathrm{PtO}_{2}$ is in the coordination number, which is $2.9 \pm 0.4$ instead of $4.8 \pm 0.6$ for $\mathrm{PtO}_{2}$, This lower coordination number indicates a higher dispersion of platinum particles on the surface of the cerium oxide support. After insitu reduction, the local environment of platinum is composed of both oxygen and platinum atoms (Figure $3 \mathrm{~b}$ and Table $\mathrm{S}_{3}$ ). The Pt-O bond distance is considerably longer than the Pt-O bond distance in $\mathrm{PtO}_{2}$ (2.10 $\pm 0.05 \AA$ compared to $2.00 \pm 0.01 \AA$ in $\mathrm{PtO}_{2}$ ), while the Pt-Pt bond distance is shorter than the Pt-Pt bond in Pt metal (2.72 \pm o.01 $\AA$ compared to $2.76 \pm 0.002 \AA$ in Pt metal). This shorter Pt-Pt bond distance compared to the metal can be explained by rehybridization of the spd orbitals in metal nanoparticles, ${ }^{39}$ which leads to an increase in the local electron density between two adjacent metal atoms and consequently to a smaller bond distance. ${ }^{40-42}$ The effect is more pronounced for smaller particles. Upon increasing the reaction temperature, the Pt-Pt metal bond distance changes slightly to $2.72 \pm 0.01 \AA\left(50^{\circ} \mathrm{C}\right), 2.70 \pm$ $0.04 \AA\left(100^{\circ} \mathrm{C}\right)$ and $2.69 \pm 0.03 \AA\left(150^{\circ} \mathrm{C}\right)$. The elongated Pt-O bond distance of $2.10 \AA$ after in-situ reduction remains stable during $\mathrm{CO}$ oxidation at $50^{\circ} \mathrm{C}$. At higher reaction temperatures, the Pt-O bond distance shifts again to lower values that are comparable to those in platinum oxide: $2.03 \pm 0.03 \AA$ at $100{ }^{\circ} \mathrm{C}$ and $2.01 \pm 0.04 \AA$ at $150{ }^{\circ} \mathrm{C}$. The contraction of this bond with temperature is consistent with $\mathrm{Pt} \mathrm{L}_{3}$ XANES spectral shapes (Figure $\mathrm{S}_{5}$ ), which also resemble more those of the oxide phase (increasing white line) with increasing temperature, indicating reoxidation of the platinum species on the surface under reaction conditions at higher temperature.

In order to interpret the anomalously large $\mathrm{Pt}-\mathrm{O}$ bond distance of $2.10 \AA$ in the in-situ reduced sample at ambient temperature, we performed full multiple scattering $a b$ initio simulations of the Pt L3 XANES spectra corresponding to different local atomic configurations around Pt (see supporting information for details). We choose interaction of the platinum species with the $\{111\}$ facet, since this orientation is most dominant in ceria nanoparticles. ${ }^{43}$ Best results were obtained for the atomic configuration shown in Figure 4 depicting a Pt4 cluster lying on top of the $\mathrm{CeO}_{2}$ (111) surface, with the three base $\mathrm{Pt}$ atoms bonded to oxygen atoms at a distance of $2.10 \AA$. The PtO model was used to simulate the spectrum relative to the as-prepared sample, where Pt-O distance is $2.01 \AA$. Figure 4 compares the experimental and simulated XANES spectra of the as-prepared, the in-situ reduced $2.5 \mathrm{wt}$ $\% \mathrm{Pt} / \mathrm{CeO}_{2}$ catalysts and the $\mathrm{PtO}_{2}$ reference. The simulations reproduce well the main features of the spectra. This is a strong indication that the local atomic configuration around $\mathrm{Pt}$ is close to that of the chosen models. Vaarkamp et.al observed such elongated Pt-O bonds, as noticed in present in-situ reduced sample, in a Pt/H-LTL zeolite catalyst after treatment at $500{ }^{\circ} \mathrm{C}$ in $\mathrm{H}_{2} .{ }^{44}$ The authors propose this distance as a characteristic of zero valent Pt in contact with oxygen from the support. Concerning the $\mathrm{Pt} / \mathrm{CeO}_{2}$ system, interaction between platinum metal and ceriumoxide via the formation of $\mathrm{Pt}-\mathrm{O}-\mathrm{Ce}$ bonds has been discussed in the literature as favorable for the catalytic activity, ${ }^{45,46}$ but to the best of our knowledge, has not been reported under operando conditions using EXAFS. In this context, our direct observation also sheds light on the oxidation state of platinum on cerium oxide. It has been observed that oxidized noble metal species can indeed be more active than the completely reduced particle. ${ }^{25,46}$ In the case of strong interaction with the support via oxygen bonds, the noble metal species is naturally in an oxidized state. DFT calculations show that the oxygen between a cerium atom and platinum is situated in a rather unusual configuration: the energy to withdraw this oxygen is strongly reduced, which might allow the participation of this oxygen in the reaction and thus encounter for the low temperature activity. ${ }^{45,46}$ Tang et al. propose this mechanism for the oxidation of methane..$^{46}$ The calculated $\mathrm{Pt}-\mathrm{O}$ bond distance in $\mathrm{Ce}-\mathrm{O}-\mathrm{Pt}$ linkage using DFT is $2.12 \AA$, i.e. quite similar to the bond distance of 2.10 $\pm 0.05 \AA$ that we observe. Our catalyst might be in a similar favorable situation as described by DFT calculations, namely with easily removable oxygen shared by ceria and platinum. 


\section{Conclusion}

We have shown that room temperature activity of $\mathrm{Pt} / \mathrm{CeO}_{2}$ catalysts can be achieved by a hydrogen pretreatment of nanosized platinum species. HAADF-STEM analysis clearly show the presence of well-dispersed nanoparticles that are not covered by ceria after hydrogen treatment, as it would be the case in a classic SMSI situation. The reduced platinum particles spread under the electron beam, suggesting strong interaction with the support. After the first catalytic cycle, no spreading is observed, which in in coherence with loss in catalytic activity after the first cycle. In-situ EXAFS show that the platinum particles are not fully reduced in the active state. The active catalyst is characterized by an elongated $\mathrm{Pt}-\mathrm{O}$ bond distance of $2.10 \pm 0.05 \AA$. Combination of EXAFS analyses and FEFF simulation suggests that the low temperature catalytic activity can be related to platinum species-ceria interaction via these elongated Pt-O bonds. Elongated $\mathrm{Pt}-\mathrm{O}-\mathrm{Ce}$ bond distances between platinum particles and ceria have been discussed in the literature. To the best of our knowledge, this is the first time that the bond distance of $\mathbf{2 . 1 0} \AA$ h has been observed in-situ. The present study contributes thus to the general understanding of support-catalyst interaction at low temperature, which opens the field for optimizing catalysts active in this temperature regime.

\section{ASSOCIATED CONTENT}

Supporting Information. The supporting information contains information on materials preparation, characterization, catalytic test, X-Ray diffraction, HAADF-STEM analysis and movies of the $\mathrm{Pt}$ particles under the electron beam, XASexperimental set-up, XAS spectra of Pt-edge and Ce-edge, and details on the FEFF9 simulation. This material is available free of charge via the Internet at http://pubs.acs.org.

\section{AUTHOR INFORMATION}

\section{Corresponding Author}

*E-mail:helena.kaper@saint-gobain.com

*E-mail: sakura@esrf.fr

\section{Author Contributions}

The manuscript was written through contributions of all authors. All authors have given approval to the final version of the manuscript.

\section{Notes}

The authors declare no competing financial interest.

\section{REFERENCES}

(1) Sidheswaran, M. a.; Destaillats, H.; Sullivan, D. P.; Larsen, J.; Fisk, W. J. Appl. Catal. B Environ. 2011, 107, 34-41.

Zhang, C.; He, H. Catal. Today 2007, 126, 345-350.
Imanaka, N.; Masui, T.; Imadzu, H.; Yasuda, K. Chem. Commun. 2011, 47, 11032-11034.

(4) Liu, H.-H.; Wang, Y.; Jia, A.-P.; Wang, S.-Y.; Luo, M.-F.; Lu, J.-Q. Appl. Surf. Sci. 2014, 314, 725-734.

Yoon, C.; Cocke, D. L. J. Catal. 1988, 113, 267-280.

Biemelt, T.; Wegner, K.; Teichert, J.; Lohe, M. R.; Martin, J.; Grothe, J.; Kaskel, S. Appl. Catal. B Environ. 2016, 184, 208215.

(7) Xie, X.; Li, Y.; Liu, Z.-Q.; Haruta, M.; Shen, W. Nature 2oog, $458,746-749$.

(8) An, N.; Yu, Q.; Liu, G.; Li, S.; Jia, M.; Zhang, W. J. Hazard. Mater. 2011, 186, 1392-1397.

(9) Tauster, S. J.; Fung, S. C.; Garten, R. L. J. Am. Chem. Soc. 1978, 170-175.

(10) Yang, M.; Liu, J.; Lee, S.; Zugic, B.; Huang, J.; Allard, L. F.; Flytzani-Stephanopoulos, M. J. Am. Chem. Soc. 2015, 137, 3470-3473.

(11) Peterson, E. J.; DeLaRiva, A. T.; Lin, S.; Johnson, R. S.; Guo, H.; Miller, J. T.; Hun Kwak, J.; Peden, C. H. F.; Kiefer, B.; Allard, L. F.; Ribeiro, F. H.; Datye, A. K. Nat. Commun. 2o14, $5,1-11$.

(12) Newton, M. a; Di Michiel, M.; Kubacka, A.; Iglesias-Juez, A.; Fernández-García, M. Angew. Chem. Int. Ed. Engl. 2012, 51, $2363-2367$.

(13) Cargnello, M.; Doan-Nguyen, V. V. T.; Gordon, T. R.; Diaz, R. E.; Stach, E. A.; Gorte, R. J.; Fornasiero, P.; Murray, C. B. Science (80-. ). 2013, 341, 771-773.

(14) Vayssilov, G. N.; Lykhach, Y.; Migani, A.; Staudt, T.; Petrova, G. P.; Tsud, N.; Skála, T.; Bruix, A.; Illas, F.; Prince, K. C.; Matolín, V.; Neyman, K. M.; Libuda, J. Nat. Mater. 2011, 10, 310-315.

(15) Bruix, A.; Migani, A.; Vayssilov, G. N.; Neyman, K. M.; Libuda, J.; Illas, F. Phys. Chem. Chem. Phys. 2011, 13, 1138411392.

(16) Montini, T.; Melchionna, M.; Monai, M.; Fornasiero, P. Chem. Rev. 2016, 5987-6041.

Bunluesin, T.; Gorte, R. J.; Graham, G. W. Appl. Catal. B Environ. 1998, 15, 107-114.

Sun, C.; Li, H.; Chen, L. Energy Environ. Sci. 2012, 5, 84758505 .

Huang, W.; Gao, Y. Catal. Sci. Technol. 2014, 4, 3772-3784.

(20) Bera, P.; Priolkar, K. R.; Gayen, A.; Sarode, P. R.; Hegde, M. S.; Emura, S.; Kumashiro, R.; Jayaram, V.; Subbanna, G. N. Chem. Mater. 2003, 15, 2049-2060. 
(21) Bera, P.; Gayen, A.; Hegde, M. S.; Lalla, N. P.; Spadaro, L.; Frusteri, F.; Arena, F. J. Phys. Chem. B 2003, 107, 6122-6130.

(22) Ke, J.; Zhu, W.; Jiang, Y.; Si, R.; Wang, Y.-J.; Li, S.-C.; Jin, C.; Liu, H.; Song, W.-G.; Yan, C.-H.; Zhang, Y.-W. ACS Catal. 2015, 5, 5164-5173.

(23) Kalamaras, C. M.; Americanou, S.; Efstathiou, A. M. J. Catal. 2011, 279, 287-300.

(24) Kalamaras, C. M.; Dionysiou, D. D.; Efstathiou, a. M. ACS Catal. 2012, 2, 2729-2742.

(25) Fu, Q.; Saltsburg, H.; Flytzani-stephanopoulos, M. Science (80-. ). 2003, 301, 935-938.

(26) Kalamaras, C. M.; Petallidou, K. C.; Efstathiou, A. M. Appl. Catal. B Environ. 2013, 136-137, 225-238.

(27) Daturi, M.; Bion, N.; Saussey, J.; Lavalley, J.-C.; Hedouin, C.; Seguelong, T.; Blanchard, G. Phys. Chem. Chem. Phys. 2oo1, 3, 252-255.

(28) Baidya, T.; Gupta, A.; Deshpandey, P. A.; Madras, G.; Hegde, M. S. Society 2009, 4059-4068.

(29) Pozdnyakova, O.; Teschner, D.; Wootsch, A.; Kröhnert, J.; Steinhauer, B.; Sauer, H.; Toth, L.; Jentoft, F. C.; Paál, Z.; Schlögl, R. J. Catal. 2006, 237, 1-16.

(30) Mariño, F.; Descorme, C.; Duprez, D. Appl. Catal. B Environ. 2004, 54, 59-66.

(31) Yao, H. J. Catal. 1984, 86, 254-265.

(32) Seo, P. W.; Choi, H. J.; Hong, S. I.; Hong, S. C. J. Hazard. Mater. 2010, 178, 917-925.

(33) Van Delft, F. C. M. J. M.; Nieuwenhuys, B. E. Solid State Ionics 1985, 16, 233-240.

（34） Gonzalez-DelaCruz, V. M.; Holgado, J. P.; Pereñíguez, R.; Caballero, A. J. Catal. 20o8, 257, 307-314.
Nagai, Y.; Dohmae, K.; Ikeda, Y.; Takagi, N.; Tanabe, T.; Hara, N.; Guilera, G.; Pascarelli, S.; Newton, M. a; Kuno, O.; Jiang, H.; Shinjoh, H.; Matsumoto, S. Angew. Chem. Int. Ed. Engl. 2008, 47, 9303-9306.

Blik, H. V.; Zon, J. Van. J. Am. Ceram. Soc. 1985, 107, 31393147 .

（37） Cafun, J. D.; Kvashnina, K. O.; Casals, E.; Puntes, V. F.; Glatzel, P. ACS Nano 2013, 7, 10726-10732.

(38) Kopelent, R.; van Bokhoven, J. a.; Szlachetko, J.; Edebeli, J.; Paun, C.; Nachtegaal, M.; Safonova, O. V. Angew. Chemie Int. Ed. 2015, 54, 8728-8731.

（39） Delley, B.; Ellis, D. E.; Freeman, A. J.; Baerends, E. J.; Post, D. Phys. Rev. B Condens. Mater. Phys. 1983, 27, 2132-2144.

(40) Stakheev, a. Y.; Zhang, Y.; Ivanov, a. V.; Baeva, G. N.; Ramaker, D. E.; Koningsberger, D. C. J. Phys. Chem. C 2007, 111, 3938-3948.

(41) Miller, J. T.; Kropf, a. J.; Zha, Y.; Regalbuto, J. R.; Delannoy, L.; Louis, C.; Bus, E.; van Bokhoven, J. a. J. Catal. 2006, 240, 222-234.

(42) Bus, E.; Miller, J. T.; van Bokhoven, J. a. J. Phys. Chem. B 2005, 109, 14581-14587.

(43) Wang, Z. L.; Feng, X. J. Phys. Chem. B 2003, 107, 1356313566.

(44) Vaarkamp, M.; Modica, F. S.; Miller, J. T.; Koningsberger, D. C. J. Catal. 1993, 144, 611-626.

(45) Yang, Z.; Luo, G.; Lu, Z.; Woo, T. K.; Hermansson, K. J. Phys. Condens. Matter 2008, 20, 035210.

(46) Tang, W.; Hu, Z.; Wang, M.; Stucky, G. D.; Metiu, H.; McFarland, E. W. J. Catal. 2010, 273, 125-137. 
Platinum nanoparticles supported on nanosized $\mathrm{CeO}_{2}$ show room temperature oxidation of CO. HAADF-STEM analysis and in-situ EXAFS combined with FEFF simulation reveal the role of support-active phase interaction at such low temperatures.

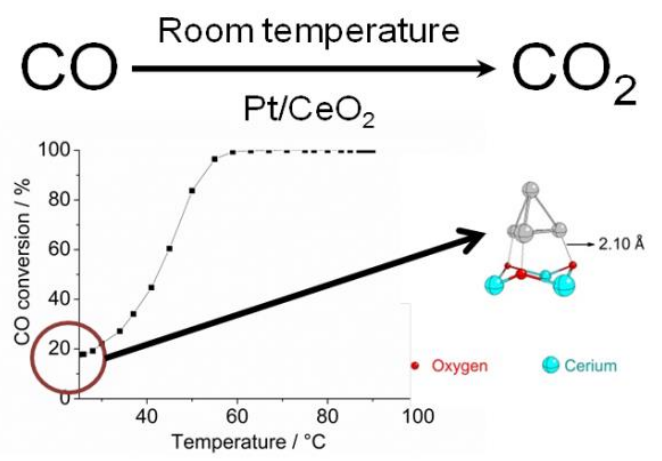

